\title{
Funções e funcionamentos da leitura em estudos apresentados no Encontro Nacional de Pesquisa em Educação em Ciências (ENPEC) de 2011 a 2017
}

\section{Reading functions and reading processes in studies presented in Brazilian Science Education Investigation Meeting (ENPEC) from 2011 to 2017}

https://doi.org/10.34112/2317-0972a2019v37n76p59-72

\author{
Maria José P. M. De Almeida ${ }^{1}$ \\ Érica Talita Brugliato ${ }^{2}$
}

ResUmo: Apontamos como objetivo deste estudo contribuir para a compreensão de como, em pesquisas apresentadas nos Encontros Nacionais de Pesquisa em Educação em Ciências (ENPECs), de 2011 a 2017, aquelas sobre leitura focalizaram a função e o funcionamento dessa atividade. Tomamos como principal apoio teórico alguns princípios e noções da Análise do Discurso, principalmente a partir de textos de Eni Orlandi, e como corpus do estudo investigações sobre leitura realizadas em situações de ensino formal e apresentadas nas quatro últimas edições do ENPEC. Concluímos apontando para a importância de que, nas pesquisas da área de Ensino de Ciências, sejam divulgados os processos seguidos ao desenvolvê-las, tanto os considerados positivos quanto aqueles que não contribuíram para que seus autores chegassem ao que esperavam.

Palavras-chave: Análise do discurso; funcionamento da leitura; função da leitura.

ABSTRACT: We aim to contribute to the understanding of how, in the investigations presented in Brazilian Science Education Investigation Meetings (ENPEC) from 2011 to 2017, reading research has focused on the function and on the process of this activity. We take as the main theoretical support some principles and notion of discourse analysis, mainly

1. Universidade Estadual de Campinas, Campinas, SP, Brasil.

2. Universidade Estadual de Campinas, Campinas, SP, Brasil. 
Funções e funcionamentos da leitura em estudos apresentados no Encontro...

from Eni Orlandi texts, and as the study corpus we take the investigations about reading carried out in formal teaching. We conclude by pointing out the relevance of the research in the area to evidence the process developed in the study, both positives and those that did not contribute to the authors reach what was expect.

KEYWORDS: Discourse analysis; reading process; reading function.

\section{INTRODUÇÃO}

Ao focalizarmos a leitura como objeto de investigação na área de Ensino de Ciências, alguns apontamentos prévios sobre essa atividade são bastante sintomáticos de características associadas ao tipo de texto proposto para leitura e ao que se pretende com ela. Silva (1981, p. 33) ressalta que "textos de natureza diversa (Literatura, Ciências, Matemática etc.), vão exigir abordagens diferentes de leitura para se chegar ao seu significado”. Além disso, quanto aos recursos com que os conhecimentos são divulgados, "é fato que um livro didático, um texto de divulgação científica, ou um original de cientista [...] não o fazem da mesma maneira nem em igual proporção" (ALMEIDA; SORPRESO, 2011, p. 84). E sobre a postura diante de um texto, Geraldi (1984) aponta quatro possibilidades: busca de informações; estudo do texto; como pretexto para outra atividade, como, por exemplo, atuar numa peça teatral; e ainda, a fruição do texto.

Ao observarmos como tem sido realizado o ensino em disciplinas da Educação em Ciências, nos seus diferentes níveis, notamos, por um lado, o quanto ele está associado à leitura, mas, por outro, não é difícil notar que muitas vezes essa atividade é utilizada apenas como meio para "apreensão" daquilo que é ensinado e que se supõe que deve ser apreendido, sem que a leitura seja propriamente pensada enquanto objeto de estudo. Nesses casos, ela é considerada uma ferramenta que deveria vir "pronta" de outras disciplinas, cursadas anteriormente.

Entretanto, nas publicações de pesquisadores da área, como em Ricon e Almeida (1991), já há bastante tempo a leitura tem sido abordada de maneira diferenciada da que descrevemos no parágrafo anterior. Ela tem sido objeto frequente de estudo em investigações na Educação em Ciências, o que justifica o presente artigo. Nele, buscamos contribuir para a compreensão de como são abordadas em pesquisas dessa área, realizadas no Brasil, questões relacionadas às funções e ao funcionamento da leitura. A abrangência com que ela vem sendo estudada pode ser notada tanto em artigos publicados em periódicos quanto nas apresentações em congressos. Nosso 
interesse é compreender como alguns dos estudos a focalizam enquanto meio para atingir determinados fins, e também se, e como, ela é estudada, com a finalidade de compreender o seu funcionamento.

Nesse sentido, assumimos como objetivo deste estudo contribuir para a compreensão de que modo, em pesquisas apresentadas nos Encontros Nacionais de Pesquisa em Educação em Ciências (ENPECs), de 2011 a 2017, aquelas que foram feitas sobre leitura focalizaram a função e o funcionamento dessa atividade.

A partir desse objetivo estabelecemos a seguinte questão:

Como em pesquisas apresentadas nos ENPECs de 2011 a 2017 são focalizados o funcionamento e as funções da leitura em situações de ensino? Partindo dessa questão, no item seguinte apresentamos alguns princípios e noções em que nos sustentamos para a realização do estudo.

\section{Apoio teóRICO-METOdológico}

Neste item, explicitamos alguns princípios e noções constitutivos do dispositivo teórico que embasou desde a construção da questão de pesquisa até o modo como analisamos os textos que compõem o corpus do estudo, pois "o suporte teórico não entra em cena apenas na análise de informações obtidas com a intenção de se solucionar um problema; as convicções que esse referencial possibilita direta ou indiretamente já se fazem presentes na definição desse problema” (ALMEIDA, 2004, p. 44).

Destacamos, da vertente pecheutiana da Análise do Discurso, primeiramente a materialidade da linguagem e a sua consideração como não transparente, além do discurso admitido como efeito de sentidos entre locutores. Sobre as palavras, destacamos que "não são só nossas. Elas significam pela história e pela língua. O que é dito em outro lugar também significa nas 'nossas' palavras" (ORLANDI, 2003, p. 32).

A mesma autora aponta que, como consequência da não transparência e da materialidade da linguagem, decorre a necessidade de dispositivos para se ter acesso a ela, de dois tipos: o dispositivo teórico da interpretação e o analítico, sendo que o primeiro vai determinar o segundo. Este, o dispositivo analítico da interpretação, é construído por cada analista, e "vai depender da questão do analista, da natureza do material analisado, do objetivo do analista e da região teórica em que se inscreve o analista" (ORLANDI, 2003, p. 26).

A autora chama de compreensão os resultados a que se chega na análise. E, ainda sobre questões metodológicas, Orlandi distingue o dado empírico e o objeto 
Funções e funcionamentos da leitura em estudos apresentados no Encontro...

científico, que é construído: "quando definimos o objeto através da metodologia, nos comprometemos ao mesmo tempo com uma teoria e com um corpo de definições, de acordo com os quais produzimos as correspondentes técnicas de análise" (ORLANDI, 1988, p. 16). Portanto, acontecimentos observados de diferentes perspectivas dão origem a diferentes objetos de conhecimento.

Sobre os sentidos, estes "não estão só nas palavras, nos textos, mas na relação com a exterioridade, nas condições em que eles são produzidos e que não dependem só das intenções dos sujeitos" (ORLANDI, 1988, p. 30). Daí, desde que aceito o papel da exterioridade sobre os sentidos, necessariamente concordamos que "o texto não é o lugar de informações - completas ou a serem preenchidas - mas é processo de significação, lugar de sentidos" (ORLANDI, 1983, p. 21).

Sobre as condições de produção, a autora afirma que elas compreendem fundamentalmente os sujeitos e a situação, sendo que a memória também faz parte da produção discursiva, ou seja, podemos "considerar as condições de produção em sentido estrito e temos as circunstâncias da enunciação: é o contexto imediato. E se as considerarmos em sentido amplo, as condições de produção incluem o contexto sócio histórico ideológico". (ORLANDI, 2003, p.30). Aqui, a ideologia é compreendida como "interpretação de sentidos em certa direção, determinada pela relação da linguagem com a história, em seus mecanismos imaginários”. (ORLANDI, 1994, p. 56). E ainda, sobre as condições de produção, elas "implicam o que é material (a língua sujeita a equívoco e a historicidade), o que é institucional (a formação social, em sua ordem) e o mecanismo imaginário" (ORLANDI, 2003, p. 40, grifo nosso). Sobre esse mecanismo, Orlandi aponta que, numa dada conjuntura, ele produz imagens dos sujeitos e do objeto do discurso.

A relevância das condições de produção na leitura é explicitada por Orlandi (1983), quando a autora afirma que o processo de leitura é configurado pelas condições do autor e do leitor. Sendo que "a leitura é o momento crítico da constituição do texto, pois é o momento privilegiado do processo da interação verbal: aquele em que os interlocutores, ao se identificarem como interlocutores, desencadeiam o processo de significação” (p. 20).

Partindo dessas noções básicas, dado nosso interesse em compreender como, nas pesquisas sobre leitura no Ensino de Ciências, são focalizados a função e o funcionamento da leitura, apontamos aqui a consideração de que, ao falar de função estamos pensando em "para que ler", ler com que finalidade, ou seja, o resultado ou produto esperado da leitura. Dada essa consideração, no que se refere à função da 
leitura, neste estudo procuramos oferecer como exemplos discursos que permitem inferir o que supostamente se espera como resultado da leitura. Não podemos, entretanto, deixar de comentar que, enquanto alguns estudos podem focalizar a leitura como uma estratégia para apreensão de determinados conteúdos de disciplinas da área de Educação em Ciências, em outros casos, algo apenas relacionado à leitura propriamente dita pode ser inferido do discurso selecionado, por exemplo: um discurso que indique se ter chegado a uma leitura crítica ou a uma contribuição para incremento do gosto por realizar essa atividade. Em qualquer dos casos, se o discurso se referir ao produto da leitura, estaremos considerando esse produto como a função a ela destinada.

Já no que se refere ao funcionamento da leitura, conforme Orlandi, "o funcionamento é a atividade estruturante de um discurso determinado, por um falante determinado, para um interlocutor determinado, com finalidades específicas". (ORLANDI, 2003, p. 22, grifos da autora). E tendo em conta nosso propósito de buscarmos em pesquisas da área de Ensino de Ciências discursos que se refiram ao funcionamento da leitura, e, portanto, discursos que remetam à sua atividade estruturante, assumimos que, nesse caso, os discursos a serem selecionados devem explicitar processos associados a essa atividade e não apenas as suas finalidades. É através de processos de leitura, ou seja, através da leitura em funcionamento de determinada maneira, que se chega ao que dela se espera, o produto, uma ou várias funções dessa atividade. Pensando no discurso, Orlandi comenta: "o tipo (produto) é funcionamento discursivo (processo) que se cristaliza historicamente, dada a dinâmica das condições de produção" (ORLANDI, 2003, p. 22).

Em síntese, no que se refere ao funcionamento da leitura, procuramos, no corpus deste estudo, que apresentamos no item seguinte, discursos com indícios de associação a processos de leitura. E quanto a discursos referentes às funções da leitura, como comentamos anteriormente, buscamos localizar exemplos dos que apontam finalidades dessa atividade.

\section{O CORPUS DO ESTUDO}

Consideramos que as publicações dos ENPEC's seriam adequadas aos nossos propósitos. Dentre as áreas acadêmicas, a de Ensino de Ciências/Educação em Ciências é relativamente recente, mas no final da segunda metade do século passado já era considerada bastante consolidada e, entre os fatores que contribuíram para 
Funções e funcionamentos da leitura em estudos apresentados no Encontro...

a sua consolidação no Brasil, um deles foi a realização de Congressos/Simpósios/ Encontros. Embora haja muitos outros, voltados para o ensino de disciplinas específicas, ocorridos antes, em 1997 foi realizado o primeiro ENPEC congregando pesquisadores de diferentes disciplinas relacionadas ao ensino das chamadas Ciências da Natureza. A partir de então, os encontros foram bianuais, num total de 11 até 2017.

A opção por selecionarmos publicações do ENPEC para o corpus desta pesquisa se deve ao fato de que as atas do encontro contêm publicações de diferentes disciplinas, à regularidade com que os encontros têm sido realizados e, principalmente, ao número de trabalhos sobre leitura que neles podem ser encontrados. Nossa busca se deu nas atas dos ENPEC's presentes no site da Associação Brasileira de Pesquisa em Educação em Ciências (ABRAPEC). Decidimos realizar este estudo com base em trabalhos apresentados nas últimas quatro edições, 2011, 2013, 2015 e 2017, quando notamos que, diferentemente dos encontros anteriores, no VIII, de 2011, uma das formas de acesso aos trabalhos é a Lista por Linha Temática, sendo uma delas Linguagens, e ensino de ciências. Nos ENPEC's seguintes, IX, X e XI, o programa continuou tendo diferentes opções para inscrição dos trabalhos. Entretanto, em vez da denominação "Linha" para as inscrições nos ENPEC's, e consequentemente nas atas, elas passaram a ser em Áreas Temáticas, sendo que uma delas manteve o foco na linguagem: Linguagens, discursos e educação em ciências.

Entendemos que buscar pelas palavras "leitura" e "leituras", nos títulos, resumos e palavras-chave dessa Linha e Áreas temáticas, dado, inclusive, o número de trabalhos encontrados numa sondagem prévia, permitiria uma boa construção do corpus. Assim, procuramos a palavra "leitura" em trabalhos nos quais os autores haviam inscrito seu estudo na linha relacionada à linguagem, devido à sondagem prévia na qual havíamos encontrado vários trabalhos. Não consideramos os estudos que se referiam a leituras de imagens, de diagramas ou estudos multimodais, pois nosso propósito era trabalhar apenas com a leitura textual verbal.

Obtivemos seis estudos no VIII ENPEC, nove no IX, sete no X e 10 no XI, num total de 30 trabalhos. Dois do ENPEC de 2017 e dois do ENPEC de 2015 são revisões de trabalhos relacionados à leitura apresentados nos ENPEC's anteriores. Cabe aqui assinalar que nosso objetivo não foi fazer uma revisão sobre leitura, mas sim buscar discursos cuja análise permitisse encontrar indicadores da focalização em funções e/ou funcionamento da leitura nas pesquisas. Entretanto, na sessão seguinte nos referimos às quatro revisões encontradas nesses ENPEC's, por termos localizado nelas aspectos relacionados ao nosso propósito. 
As ReVISÕes ENCONTRADAS

Andrade et al. (2015) descrevem o perfil de vários aspectos das produções sobre leitura apresentadas nas edições do ENPEC até a de 2013. Entre esses aspectos, destacamos que "a maioria dos trabalhos não especifica o referencial teórico e/ ou metodológico, enquanto que um terço utiliza a Análise de Discurso Francesa” (ANDRADE, 2015, p. 1). Consideramos interessante destacar esse aspecto pela coincidência do referencial desse um terço dos trabalhos com o do estudo que aqui apresentamos. Além disso, as conclusões desse trabalho, ao apontarem para a crescente valorização, por pesquisadores, do "papel da linguagem como constitutiva de identidades, sentidos e práticas educativas; do papel de textos como mediadores culturais e da alfabetização/letramento científico como objetivo para o ensino de ciências" (ANDRADE, 2015, p. 8), dado que se trata de uma revisão de trabalhos sobre leitura, evidenciam a relevância de procurarmos compreender aspectos das funções e do funcionamento da leitura nesses estudos.

Numa das revisões de 2017, Andrade e Martins (2017) buscam descrever discursos sobre leitura na Educação em Ciência analisando trabalhos apresentados em edições anteriores do ENPEC. Com esse propósito, dos 87 trabalhos referentes à leitura que encontraram nas edições de 1997 a 2015, selecionaram dez por cento para, com noções do apoio teórico metodológico da Análise Crítica do Discurso, descreverem os discursos que tratam objetivos e sentidos da leitura a partir de relações intertextuais.

Dado que um de nossos focos está associado às funções que os autores de publicações dos ENPEC's atribuem à leitura, notamos no estudo dessas autoras que, ao abordarem significados a ela atribuídos pelos autores dos artigos que analisaram, apresentam trechos como: "um dos significados atribuídos para a leitura foi enunciado como uma 'ação cognoscitiva' mediada tanto pelo ambiente quanto pela cultura pessoal [...] abordam a leitura como processo de aprendizagem da ciência [...] Nessa perspectiva, ler instrumentaliza o estudante" (ANDRADE; MARTINS, 2017, p.8). Destacamos ainda, de suas considerações finais, o trecho: "o sentido de leitura é abordado por alguns autores como meio para instrumentalizar o estudante para decodificação da língua e também como processo que possibilita a interpretação e formação do cidadão articulador com o meio social” (ANDRADE; MARTINS, 2017, p. 9).

Na outra revisão relativa à leitura, apresentada no XI ENPEC, Araújo et al. (2017) focalizaram quarenta trabalhos das edições do ENPEC de 2005 até 2015. Os autores apontam a análise de conteúdo como sua perspectiva metodológica e, da descrição 
que fazem da leitura no Ensino de Ciências nos trabalhos das edições de 2005, 2009 e 2011, destacamos um trecho que consideramos de interesse para um estudo no qual assumimos como um dos focos a função da leitura nas pesquisas em Ensino de Ciências: a leitura "enquanto mediadora da compreensão do saber científico e a leitura como forma de acesso e representação desse saber” (Op. Cit. p. 6). Com relação às descrições que eles fazem do ENPEC de 2013, destacamos: "nas relações da leitura e ciências, aquela assume papéis de contribuir na formação e interpretação de conceitos científicos, na produção de sentidos, estudo das condições de produção de discursivos relacionados à abordagem da ciência” (Op. Cit. p. 7). Considerados os dois trechos destacados, notamos a leitura com diversas funções: mediadora para compreensão do saber científico, forma de acesso e de representar esse saber, maneira de formar e interpretar conceitos científicos, de produzir sentidos e de estudar condições de produção de discursos relacionados à abordagem da ciência.

Ainda com relação a revisões/levantamentos sobre pesquisas apresentadas nos ENPEC's, citamos aqui o trabalho de Palcha e Cabral (2015), que faz um levantamento sobre a relação entre literatura e ciência nas edições de 1997 até 2013. Nessa pesquisa, os autores dizem que sua perspectiva teórica, metodológica e analítica se fundamentou na Análise do Discurso francesa e, desse levantamento, dado nosso interesse nas funções da leitura, destacamos: "foram encontradas quinze pesquisas, as quais denotam que o ponto de articulação entre Literatura e Ciência firma-se pela criatividade que a leitura produz" (PALCHA; CABRAL, 2015, p. 1, grifo nosso). Ao escreverem "o que a leitura produz", os autores consideram que realizá-la em obras literárias teria como função provocar a criatividade.

Neste item, em revisões encontradas no corpus deste estudo focalizamos algumas informações relativas ao uso/não uso de apoios teórico-metodológicos e destacamos trechos que nos permitiram inferir diversas funções da leitura. Nos itens seguintes, além de selecionarmos mais alguns trechos que indicam funções da leitura em trabalhos dos ENPEC's, voltamos nossa atenção também para o funcionamento da leitura.

\section{FunÇões da LEITURA EM SITUAÇões DE ENSINO FORMAL}

Aqui, inicialmente nos detemos em alguns trechos de artigos dos quatro ENPEC's que fazem parte do corpus deste estudo, para ilustrar como nesses trechos podemos inferir propósitos do trabalho com a leitura, visando determinadas 
funções dessa atividade. Optamos também por buscar exemplos em investigações realizadas em situações de ensino formal.

No seguinte trecho do artigo de Resende e Kautau-Guimarães (2011), "a leitura de livros e artigos de divulgação científica pode estimular e atualizar tanto professores como estudantes de graduação" (p.7), fica explícita a preocupação com a função estimuladora e atualizadora da leitura.

Num outro exemplo, um trecho de uma comunicação em que é descrita uma atividade de leitura realizada com estudantes universitários do primeiro ano, na disciplina Ciências da Natureza, notamos a função da leitura como meio para compreensão sobre o imaginário dos estudantes a respeito do conhecimento científico: "a fim de estudar a relação entre a leitura e a visão dos alunos sobre o conhecimento científico” (RAMOS; PIASSI, 2013, p. 4). E quando os autores apontam características dessa mesma comunicação, destinada à leitura, podemos indiretamente notar que a função da leitura seria propiciar determinadas posições em relação à ciência e à sociedade: "o que se torna fundamental na obra é a presença de críticas e ironias em relação à ciência e à própria sociedade" (RAMOS; PIASSI, 2013, p. 7).

De acordo com Sedamo e Carvalho (2015), que estudaram a importância e características da leitura, além da aproximação com o conceito, o procedimento de leitura, "quando inserido no ambiente de ensino de Ciências por investigação, provoca o educando a refletir sobre a problemática proposta na leitura, pensar criticamente, tomar posição embasado na relação com o que é apresentado no texto e seus conhecimentos prévios" (p. 3). Nesse trecho, as autoras se referem a funções da leitura, se inserida no contexto do "ensino por investigação".

No trecho extraído do artigo de Santos-Goedert e Rocha (2017), no qual os autores buscam demonstrar a associação entre a leitura de mundo e a leitura da palavra proposta por Paulo Freire, na produção de conhecimentos próprios à visão de mundo infantil notamos a seguinte função da leitura referente a essa atividade realizada pelos alunos: "com leituras sobre os estudos de Isaac Newton, descobriram a cor da luz do sol e a decomposição dela para formar o arco-íris na atmosfera" (p. 5). Podemos notar aí a função da leitura associada aos propósitos dos autores.

Até aqui procuramos apenas mostrar alguns exemplos de funções da leitura presentes em artigos de pesquisadores da área de Ensino de Ciências. Esses poucos exemplos certamente não esgotam as múltiplas funções que podemos encontrar para essa atividade em pesquisas dessa área. Mas não é nosso objetivo esgotar todas as possibilidades; apenas nos propusemos apresentar alguns exemplos num 
Funções e funcionamentos da leitura em estudos apresentados no Encontro...

espectro variado. Precisamos também esclarecer que o fato de termos destacado trechos relativos a funções não significa que no artigo em que a função foi destacada não houvesse a preocupação com o funcionamento da leitura. Sobre ele, entretanto, apresentamos exemplos no próximo item.

\section{FunCiOnAMENTO DA LEITURA EM SITUAÇÕES DE ENSINO FORMAL}

No item anterior, buscamos exemplos de funções da leitura em pesquisas de quatro edições do ENPEC que abordaram a leitura em situações formais de ensino. Aqui, mantemos o propósito de buscar exemplos em pesquisas realizadas em situações formais de ensino, agora voltado a evidenciar o funcionamento da leitura. Nesse sentido, selecionamos dois exemplos em trabalhos do último ENPEC, o de 2017.

No intuito de identificarmos o funcionamento da leitura, ou seja, processos em que ela teria ocorrido nesses estudos, contribuindo para que os estudantes estabelecessem processos de significação, resgatando sentidos no texto lido, procuramos nas investigações, basicamente, as condições de produção das atividades realizadas com os estudantes. Com isso, não estávamos descartando o papel das condições sócio-históricas de cada estudante na produção de sentidos ao realizarem a leitura, mas admitimos que nas condições imediatas, ou seja, na descrição da atividade realizada pelos estudantes, encontraríamos fatores que teriam contribuído para configurar o processo de produção da leitura.

Araújo e Carneiro (2017) propõem a alunos de um curso de Educação de Jovens e Adultos (EJA) a leitura de textos nos quais é possível encontrar contradições e incluem como condição de produção dessa leitura, basicamente, que os estudantes apontem as dificuldades encontradas. As autoras propõem como objetivo investigar se os alunos da EJA apresentam dificuldades de leitura de textos que veiculam conhecimentos científicos e tecnológicos e, em caso positivo, identificá-las. Ao analisarem as informações coletadas, concluem que a maioria dos alunos tem dificuldades em identificar contradições e, inclusive, em identificar e descrever suas dificuldades.

Notamos, desse modo, como, nesse estudo, as autoras buscaram compreender aspectos do processo de leitura desses estudantes. E nas suas considerações finais esse aspecto fica explícito quando elas apontam a necessidade de entendimento pelo aluno do que está lendo, e afirmam que, caso isso não ocorra, "que ele seja capaz de perceber que não entendeu e adotar estratégias para resolver o problema" (ARAÚJO; CARNEIRO, 2017, p. 9). 
Numa outra pesquisa à qual nos referimos para exemplificar o foco dos autores no funcionamento da leitura, Targino e Giordan (2017) assumem que, para que textos de divulgação científica possam despertar o interesse dos estudantes por temas científicos ou prover uma visão crítica de ciência, entre outros possíveis benefícios a que se referem, é preciso considerar como o discurso de divulgação científica é apresentado em sala de aula. Partindo dessas considerações, os autores analisam os movimentos discursivos de uma professora numa aula de química, em que ela retextualiza um texto literário de divulgação científica. Dessa retextualização, focalizam principalmente a realização de uma atividade experimental, parte da qual apresentam num quadro. Consideramos que, dessa forma, ilustram o funcionamento discursivo da professora em parte da aula, quando apresentam, no quadro, de um lado o discurso-fonte, e do outro os discursos correspondentes da professora ao mostrar a atividade experimentalmente.

Destacamos das considerações finais dessa pesquisa o seguinte trecho: "durante os processos de retextualização que analisamos, foram evidenciados e explicitados o sentido de termos implícitos [...] assim como durante a atividade experimental demonstrativa foram ilustradas as ações que estavam narradas no trecho" (TARGINO; GIORDAN, 2017, p. 8). Ele mostra como a retextualização e a atividade prática foram utilizadas com o intuito de modificar o funcionamento da leitura, funcionamento que os autores admitiram depender do que fosse feito em sala de aula.

\section{Algumas considerações}

Orlandi (1984) considera que a leitura é um processo, que os sentidos têm sua história e aponta a importância da interdiscursividade, ou seja, do fato de que um texto tem relação com outros textos. Sendo assim, a interpretação possível se relaciona à história de leitura de cada um, e as leituras já feitas podem tanto alargar quanto restringir a compreensão de um texto. E referindo-se ao leitor, a autora propõe que "o possível e o razoável, em relação à compreensão de um texto, se definam levando-se em conta as histórias da sua leitura, na forma de interação que o leitor estabelece, no processo de leitura." (p. 8). Vale dizer que a autora considera o possível como limite.

Ao nos voltarmos para o ensino formal na área de Ensino de Ciências, e tendo em conta essa definição de Orlandi, bem como o anteriormente referido de Silva (1981) sobre a exigência de abordagens diferentes para textos de naturezas diferentes, notamos a relevância de compreendermos diferentes funcionamentos 
Funções e funcionamentos da leitura em estudos apresentados no Encontro...

possíveis da leitura em situações de ensino. Aqui apontamos dois exemplos a partir das pesquisas selecionadas.

Com isso, não estamos descartando a importância de pensarmos as funções da leitura. Admiti-las e supor sua possível abrangência é uma necessidade na organização de um trabalho pedagógico que inclua essa atividade. Acreditamos, entretanto, na relevância de, em situações de ensino, nos debruçarmos sobre o seu funcionamento, sobre o possível percurso dos estudantes enquanto leem. E temos notado, em algumas investigações, que nem sempre esse aspecto é valorizado nos relatos apresentados.

Por outro lado, no que se refere às funções que a leitura teria desempenhado, frequentemente apenas são apontados os resultados considerados positivos. Julgamos, entretanto, que o detalhamento de propostas e efetivação dos processos ocorridos, tanto do que funcionou de acordo com as expectativas, quanto daquilo que não ocorreu como se esperava, pode ser de grande contribuição para inspirar outros trabalhos.

\section{REFERÊNCIAS}

ALMEIDA, M. J. P. M.; Discursos da Ciência e da Escola: ideologia e leituras possíveis. Campinas: Mercado de Letras, 2004.

ALMEIDA, M. J. P. M.; SORPRESO, T. P. Dispositivo analítico para compreensão da leitura de diferentes tipos textuais: exemplos referentes à Física. Pro-Posições, v. 22, n. 1, 2011. Disponível em: <http://www.scielo.br/pdf/pp/v22n1/o8> Acesso em: 30 out. 2018

ANDRADE, I. B. et al. Uma análise dos trabalhos apresentados no ENPEC sobre Leitura e Educação em Ciências. In: X Encontro Nacional de Pesquisa em Educação em Ciências, 24 a 27/11 2015, Águas de Lindóia, SP. Disponível em: <http://www.abrapecnet.org.br/enpec/x-enpec/anais2015/ resumos/R1727-1.PDF> Acesso em: 30 out. 2018

ANDRADE, I. B.; MARTINS, I. A leitura na pesquisa em Educação em Ciências: análise de aspectos intertextuais em trabalhos apresentados no ENPEC. In: XI Encontro Nacional de Pesquisa em Educação em Ciências, 03 a 06/o7 2017, Florianópolis, SC. Disponível em: <http://www. abrapecnet.org.br/enpec/xi-enpec/anais/resumos/R1336-1.pdf> Acesso em: 30 out. 2018

ARAÚJO, M. S. et al. Abordagem da leitura no ensino de ciências: um estudo a partir das pesquisas produzidas nos Encontros Nacionais de Pesquisas em Educação em Ciências (ENPEC's) - 2005 a 2015 In: XI Encontro Nacional de Pesquisa em Educação em Ciências, 03 a o6/o7 2017, Florianópolis, SC. Disponível em: <http://www.abrapecnet.org.br/enpec/xi-enpec/anais/resumos/R1941-1. pdf > Acesso em: 30 out. 2018.

ARAÚJO, S. P.; CARNEIRO, M. H. S. Avaliação da compreensão de leitura de textos científicos na Educação de Jovens e Adultos - EJA. In: XI Encontro Nacional de Pesquisa em Educação em Ciências, 03 a 06/o7 2017, Florianópolis, SC. Disponível em: <http://www.abrapecnet.org.br/ enpec/xi-enpec/anais/resumos/R1941-1.pdf> Acesso em: 30 out. 2018. 
GERALDI,J.W. (1984). Prática da leitura de textos na escola. Leitura Teoria e Prática, n. 3, p. 25-32, 1984. ORLANDI, E. P. A produção da leitura e suas condições. Leitura, Teoria e Prática. v. 2, n. 1, p. 20-25, 1983. . As histórias da Leituras. Leitura, Teoria e Prática. v. 3, n. 3, p. 7-9, 1984.

. Discurso \& Leitura. São Paulo: Cortez Editora, 1988.

.Discurso, imaginário social e conhecimento. Em aberto, n. 14 (61), p. 52-59, 1994. Disponível em: <http://emaberto.inep.gov.br/index.php/emaberto/article/view/1943/1912> Acesso em: 30 out. 2018

. Análise de Discurso: princípios e procedimentos. Campinas: Pontes, 2003.

ORLANDI, E. P. LAGAZZI-RODRIGUES, S. (Org.) Discurso e Textualidade. Campinas: Pontes, 2006. PALCHA, L. S.; CABRAL, W. A. Literatura e Ciência: projeções possíveis nas pesquisas da área de ensino. In: X Encontro Nacional de Pesquisa em Educação em Ciências, 24 a 27/11 2015, Águas de Lindóia, SP. Disponível em: <http://www.abrapecnet.org.br/enpec/x-enpec/anais2015/ resumos/Ro913-1.PDF Acesso em: 30 out. 2018

RAMOS, J. E. F.; PIASSI, L. P. Humor, ciência, literatura e tudo mais: O Guia dos Mochileiros das Galáxias no Ensino de Ciências. In: IX Encontro Nacional de Pesquisa em Educação em Ciências, 10 a 13/11 2013, Águas de Lindóia, SP. Disponível em: <http://www.nutes.ufrj.br/abrapec/ixenpec/ atas/resumos/R1471-1.pdf >. Acesso em: 20 nov. 2018.

RESENDE, T. A.; KLAUTAU-GUIMARÃES; A divulgação científica como estratégia de ensino dos principais conceitos básicos de genética. In: VIII Encontro Nacional de Pesquisa em Educação em Ciências, 5 a 9/12 2011, Campinas, SP. Disponível em: <http://www.nutes.ufrj.br/abrapec/ viiienpec/resumos/R1056-1.pdf >. Acesso em: 20 nov. 2018.

RICON, A. E.; ALMEIDA, M. J. P. M. Ensino da física e leitura. Leitura Teoria e Prática, Campinas, v. 10, n. 18, p. 7-16, 1991.

SANTOS-GOEDERT; ROCHA, A.L. F. Da leitura da palavra à leitura de mundo: Uma possibilidade poética entre alfabetizações nos anos iniciais do Ensino Fundamental. In: XI Encontro Nacional de Pesquisa em Educação em Ciências, 03 a 06/o7 2017, Florianópolis, SC. Disponível em: <http:// www.abrapecnet.org.br/enpec/xi-enpec/anais/resumos/R1941-1.pdf>. Acesso em: 30 out. 2018.

SEDAMO, L.; CARVALHO, A. M. P. Ler e compreender nas aulas de Ciências: uma análise. In: $X$ Encontro Nacional de Pesquisa em Educação em Ciências, 24 a 27/11 2015, Águas de Lindóia, SP. Disponível em: <http://www.abrapecnet.org.br/enpec/x-enpec/anais2015/resumos/R1850-1. PDF $>$. Acesso em: 20 nov. 2018.

SILVA, E. T. O Ato de Ler: fundamentos psicológicos para uma nova pedagogia da leitura. São Paulo: Cortez Editora Autores Associados, 1981.

TARGINO, A. R. L.; GIORDAN, M. Prática de leitura em aulas de química: retextualização de textos literários de divulgação científica. In: XI Encontro Nacional de Pesquisa em Educação em Ciências, 03 a 06/o7 2017, Florianópolis, SC. Disponível em: <http://www.abrapecnet.org.br/ enpec/xi-enpec/anais/resumos/R1941-1.pdf $>$ Acesso em: 30 out. 2018. 
Funções e funcionamentos da leitura em estudos apresentados no Encontro...

SObre AS AUtoras

Maria José P. M. de Almeida possui Licenciatura em Física; Mestrado em Psicologia e Doutorado em Ciência (Universidade de São Paulo) e Livre Docência e Titular em Metodologia de Ensino-Física (Universidade Estadual de Campinas). É professora pesquisadora na Universidade Estadual de Campinas. Tem experiência em Educação em Ciências com pesquisas em Ensino de Ciências/Física e Linguagens; Formação de Professores e Ensino e Práticas Culturais. É bolsista de produtividade em pesquisa $1 \mathrm{~B}$ do Conselho Nacional de Desenvolvimento Científico e Tecnológico - CNPq.

E-mail: mjpmalmeida@gmail.com.

Érica Talita Brugliato possui Licenciatura em Física (Universidade Estadual Paulista) e Mestrado em Ensino de Ciências (Universidade Estadual de Campinas). É doutoranda do Programa de Pós-Graduação Multiunidades em Ensino de Ciências e Matemática (PECIM) da Universidade Estadual de Campinas. É bolsista da Coordenação de Aperfeiçoamento de Pessoal de Nível Superior - CAPES.

E-mail: ericabrugliato@gmail.com.

Recebido em 21 de novembro de 2018 e aprovado em 26 de junho de 2019. 